\title{
Dominación y violencia masculina en la obra cuentística de Inés Arredondo: un acercamiento.
}

\author{
Male dominance and male violence in the short stories of Inés \\ Arredondo: an approach.
}

Esta obra está bajo una Licencia Creative Commons Atribución 4.0 Internacional. DOI: $\underline{10.32870 / \text { sincronia.axxii.n74.11b18 }}$

\author{
Didier Machillot \\ Universidad de Guadalajara \\ dmachillot@hotmail.com \\ (MÉXICO)
}

Recibido: $21 / 03 / 2018$

Revisado: $23 / 04 / 2018$

Aprobado: 13/06/2018

\section{RESUMEN}

Aclamada por la crítica, la obra de Inés Arredondo está marcada profundamente, como han destacado numerosos especialistas, por la preponderancia de una visión femenina. Sin embargo, pocos estudios literarios han abordado específicamente los temas de la violencia y la dominación masculina que sufren los personajes femeninos en los textos de esta autora. No obstante, como se demostrará en este artículo, la violencia contra las mujeres, real o simbólica, ejercida por los hombres o incluso, a mayor escala, por una cultura falocéntrica, es un tema recurrente en los relatos de Arredondo, en los que es posible constatar, de manera lúcida y pesimista, las realidades de la condición femenina y, en mayor medida, de nuestra relación con el Otro, al mismo tiempo que ponen de manifiesto el "orden" falocéntrico que estructura y regula los universos en los que evolucionan los personajes de esta autora. Esperamos, pues, que identificar dicho "orden" de forma crítica nos ayude a ofrecer nuevos elementos para poder analizar más detalladamente los relatos de Arredondo en investigaciones futuras.

Palabras clave: Inés Arredondo. Literatura. Violencia. Dominación masculina. Condición femenina.

\section{ABSTRACT}

Acclaimed by several critics, the work of Inés Arredondo is deeply embedded by the prevalence of a feminine vision. However, very few literary studies have addressed the topics of violence and male 
dominance suffered by Arredondo's female characters. Nonetheless, as this paper will demonstrate, violence against women, real or symbolic, exercised by men or even to a greater extend, by a phalocentric culture, is a recurrent theme in Arredondo's stories, where it possible to become aware, in a lucid and pessimistic manner, of the realities of the condition of women and, to a greater extent, of our relation with the Other, which, at the same time, brings to light the phalocentric "order" that structures and governs the universes in which the author's characters evolve. We do hope that by identifying said "order" in a critical manner will help us offer new elements to analyze Arredondo's stories in greater detail in future researches.

Keywords: Inés Arredondo. Literature. Violence. Male dominance. Women's condition.

Perteneciente a la llamada "Generación del medio siglo", Inés Arredondo publicó tres antologías de cuentos: La señal, en 1965, Río subterráneo, en 1979, y Los Espejos, en 1988. En el mismo año, Siglo Veintiuno Editores publica sus obras completas, bajo el título Inés Arredondo, donde, además de la narrativa, se incluyen un ensayo sobre Jorge Cuesta, Acercamiento a Jorge Cuesta, y un texto presentado por la autora en el Palacio de Bellas Artes en 1966, titulado La verdad o el presentimiento de la verdad. A la cuarta edición (Labastida, 2002), prologada por Rose Corral y Rogelio Arenas Monreal, es a la que nos referiremos en el presente trabajo ${ }^{1}$.

Si bien numerosos especialistas ${ }^{2}$, han destacado la preponderancia de una visión narrativa femenina en la obra de Arredondo y observado la transgresión del orden falocéntrico resultante, pocos se han dedicado específicamente al tema de la violencia masculina que sufren algunos personajes en su obra. Como destacara Rogelio Arenas Monreal, en su prólogo a las obras completas, el orden al que se enfrentan y del que precisamente intentan liberarse las heroínas de los relatos de esta escritora, es, por lo general, impuesto por el hombre y, a través de éste, por una

\footnotetext{
${ }^{1}$ El presente artículo, traducido del francés al español por Omar González González toma como punto de partida un trabajo preliminar, inédito, titulado Visions féminines de la domination masculine ? Genre et écriture dans l'œuvre d'Inés Arredondo (Machillot, 2006), presentado como tesis de posgrado en la Universidad de Poitiers, Francia.

2 Por citar solo algunos: Rogelio Arenas Monreal, enfocado sobre el tema de la mirada (2002); Rose Corral, trabajó el concepto de lo sagrado (2002); Fabienne Bradu, examinó la relación entre la mujer y la escritura (1987); Alfredo Pérez Pavón, analizó la desaparición del "yo" en La sunamita (1988); Miriam Mabel Martínez (2004), abordó el tema de la transgresión; Angélica Tornero (2008), estudió el tema del mal; María Alicia Garza, desde una perspectiva de la escritura femenina (2001); finalmente, conviene recordar las críticas siempre constructivas de Christopher Domínguez Michael (1996) o Alberto Paredes (1990), así como el libro de Claudia Albarrán (2000) que, más allá de su enfoque biográfico, constituye una valiosa guía de análisis de la obra de Arredondo.
} 
sociedad falocéntrica que se distingue por su violencia. Al respecto, nos preguntamos ¿cómo se ejerce esta dominación masculina? y ¿cómo se manifiesta esta violencia hacia las mujeres? Para tratar de responder dichas interrogantes, nos apoyaremos tanto en los estudios de género, como en el psicoanálisis, especialmente en Lacan, así como en la sociología de Bourdieu, entre otros.

En el siguiente trabajo, se procurarán analizar en los cuentos de Inés Arredondo las leyes y las prohibiciones derivadas del orden falocéntricos, con el fin de constatar que éste es intrínsecamente violento.

\section{1. "En el nombre del padre"}

Basta recordar el Levítico y su condena del incesto para comprender la estructura profundamente religiosa del pensamiento occidental. Se comprenden mejor, entonces, la omnipresencia en el discurso psicoanalítico de la palabra "ley", término que nos recuerda las tablas y los mandamientos del Antiguo Testamento, e incluso la referencia explícita al Credo católico que se hace con la expresión "en el nombre del padre".

En este sentido, según Lacan (1978), la ley paterna estructura todos los significados del lenguaje, lo que la convierte en un principio organizador de la cultura. De ese modo, afirma en El yo en la teoría de Freud y en la técnica del psicoanálisis ${ }^{3}$, que el orden simbólico es en esencia androcéntrico (1978). Dicho "orden", Ilamado "simbólico" y claramente falocéntrico, consiste, como lo precisa Judith Butler (2005) en El género en disputa ${ }^{4}$, en un conjunto de leyes que regulan el parentesco y el significado, así como las diferenciaciones sexuales.

Inspirado en los escritos de Freud y Lévi-Strauss, Lacan afirma además que el origen de este orden es la Ley paterna que prohíbe el incesto entre la madre y su hijo. De ese modo, las bases de la construcción del individuo están condicionadas por una prohibición paterna.

\footnotetext{
${ }^{3}$ Citado en francés en el original: Le moi dans la théorie de Freud et dans la technique de la psychanalyse. N. d. t.

${ }^{4}$ Citado en francés en el original: Trouble dans le genre. N. d. t.
} 
El uso, particularmente en el psicoanálisis y en la filosofía, de un léxico y de conceptos tomados de una religión monoteísta $y$, en sentido más amplio, de una cultura grecolatina profundamente falocéntricas, aunque suscite algunas reservas ${ }^{5}$, constituye a su vez una prueba de la predominancia de ciertos modelos en nuestra cultura.

La evidencia de lo anterior, se aprecia en la obra de Arredondo como en la de muy pocos autores: en el cuento La sunamita (Arredondo, 2002a) el discurso del "tío" es intrínsecamente religioso, del mismo modo en que su imagen es consubstancial a la del padre; en Canción de cuna, aunque el padre de Erika solo aparece una vez, su intervención es especialmente violenta: "el padre se encoleriza, la madre ruega" (2002a, p.56) ${ }^{6}$, y nos remite una vez más al imaginario religioso, al estar la mujer obligada a rogarle a un dios colérico e intransigente.

Según las observaciones de Octavio Paz, el padre nunca es "paternal", sino que, por el contrario, personifica la fuerza bruta. Ello se puede observar en los cuentos de Olga y Mariana, donde queda patente que el "nombre del padre" es ante todo un "no de parte del padre": en el primero, el padre obliga a Olga a casarse y, en el segundo, por el contrario, el padre de Mariana grita y golpea, tratando de evitar por todos los medios su matrimonio:

Anoche le pegó su papá [...]. El papá gritó y Mariana dijo que por nada del mundo dejaría a Fernando. Entonces don Manuel le pegó. Le pegó en la cara como tres veces. (Arredondo, 2002a, p.99)

Un "no del padre" que es también, como destaca muy bien Judith Butler (2005), una instancia normativa en extremo heterosexual y homofóbica. Así pues, en Opus 123, el padre repudia a su hijo homosexual: "su padre se avergonzaba de él" (Arredondo, 2002b, p.244) y le reclama a su mujer un hijo "hombre": "Haz lo que quieras con tu... monigote. A mí no me sirve. Yo necesito hombres..."

\footnotetext{
${ }^{5}$ Es el caso de Pierre Bourdieu, quien afirma en La dominación masculina (2007, p. 140): “Y el analista el más sabio (un Kant o un Sartre, un Freud o incluso un Lacan...) corre por tanto el peligro de extraer, sin saberlo, de un inconsciente impensado, los instrumentos de pensamiento que utiliza para intentar pensar el inconsciente".

${ }^{6}$ Esta violencia acompaña a todos los demás personajes masculinos de este cuento. El profesor se enfada cuando descubre que la hija de Erika habla alemán e incluso llega a preguntarlo de manera agresiva: "preguntó con violencia el viejo profesor" (Arredondo, 2002, p.55).
} 
(Arredondo, 2002b, p.230). El conflicto adquiere incluso rasgos edípicos y los insultos fluyen cuando teme que su esposa lo abandone en defensa del hijo infame: "No vas a dejarme por ese marica, por ese homosexual..." (Arredondo, 2002b, p.232). Y es que el padre se siente el garante del orden y de la moral. Él es el representante del derecho divino y él es quien impone el castigo que debe caer sobre los que se desvían de la norma: Mariana, en el cuento del mismo nombre, debe fugarse para escapar de la prohibición paterna y poder casarse con el hombre que ama, mientras que en Opus 123 Feliciano es expulsado del hogar paterno debido a su homosexualidad.

Se podría entonces, sentir una suerte de alivio por la ausencia física del padre en algunos relatos. Sin embargo, al hacerlo se estaría olvidando otro tipo de presencia aún más inquietante, debido a su carácter en extremo pernicioso; una forma de autoridad ejercida con mayor eficacia, puesto que el sujeto que no está de cuerpo presente se eleva a la categoría de dios omnipotente.

La casa de los espejos, ofrece un buen ejemplo de progenitor a la vez temido e idealizado. Roberto, abandonado con su madre cuando era niño, ha construido su personalidad a partir de un concepto rígido de la virilidad que le hace comportarse como un tirano con su medio hermano: "yo le había hablado como un déspota y al menos eso había entendido" (Arredondo, 2002a, p.81); y con su esposa: "ella no tuvo más remedio que doblegarse, obediente" (Arredondo, 2002a, p.85).

El reencuentro de Roberto con el padre moribundo está, por supuesto, sellado por la decepción, ya que, aunque lo odia, no esperaba encontrar en el antiguo amante de su madre nada menos que un poderoso rival:

Su voz aflautada, no sé si por la agonía o por la vejez, me traía ecos imposibles de relacionar: era necesario que hubiera tenido una hermosa voz, fuerte y rotunda, de la cual mi madre se sintiera enamorada, con la que la había convencido de que firmara y cuyo recuerdo ensordeciera en ella cualquiera otra voz, la mía. Este andrajo tenía que haber sido un verdadero hombre, capaz de orillarla a sumirme en mi orfandad monstruosa. (Arredondo, 2002a, p.84) 
Esta escena permite adivinar un Edipo mal resuelto; una madre adorada y un padre que inspira miedo y a la vez celos, a pesar de su ausencia, pero sobre todo a causa de ésta.

Conviene entonces reconocer que, en la obra de Arredondo, el padre representa al enemigo, puesto que se impone por la violencia: es "la cara enemiga" (Arredondo, 2002b, p.234) de Feliciano el hijo homosexual, es el enemigo de Rodrigo, el niño abandonado, y, especialmente, es el enemigo de Olga y Mariana; pero también es el "enemigo amado" (Arredondo, 2002c, p.186) de las mujeres de Atrapada o de El amigo.

\section{Del falo al pene}

Como destaca Bourdieu, en el imaginario popular, el falo suele a veces simbolizar por sí solo toda la potencia masculina (2007, p. 24-25).

Es por ello que cuando se sospecha que Flavio, el marido rechazado por Olga en el cuento del mismo nombre, es impotente porque no pudo desflorar a su joven esposa, éste se vuelve objeto de toda clase de burlas.

Al haber perdido su aura de virilidad, ya no se le considera un hombre, lo rechazan hasta los marginales y lo ridiculizan las prostitutas:

Ante la cortina hecha con hileras de pequeños caracoles, vaciló un poco. Le chocó el ruido, las carcajadas brutales que venían de dentro. Porque no era la primera vez que entraba a la casita, esta noche le era especialmente repugnante ir. Pero entró.

No tuvo que buscar mucho. En una mesa del centro estaba Flavio en mangas de camisa, sucio, con una sonrisa estúpida en la cara.

- Pichoncito -le decía una chiquilla esmirriada que le tenía pasado un brazo sobre los hombros-, yo te puedo dar un certificado de que si tu mujer no te quiere no es porque no puedas.

Los parroquianos se rieron, menos Flavio que seguía igual, con su aire cretino en medio de las burlas; sin embargo, se notaba que no estaba borracho. Todos esperaban el próximo 
chiste que se haría sobre él y su situación, porque aquel espectáculo debía durar desde hacía mucho y Flavio parecía resignado a que continuara siempre.

Él que se rebajaba así y encima permitía que lo escupieran se lo merecía todo. (Arredondo, 2002a, p.38)

Si las mujeres participan también en estas humillaciones públicas, es porque la virilidad, según Bourdieu, no está ausente de las conversaciones femeninas (2007, p.68). En este caso, más que una venganza, se trata de una forma de estigmatización social, de un rechazo hacia aquello que ya no pertenece a la norma falocéntrica. Así pues, las burlas de una prostituta permiten medir hasta qué punto el poder masculino gira alrededor del órgano sexual y cómo éste deviene su símbolo principal.

Esta creencia se encuentra también ilustrada en el cuento En la sombra, por una gestualidad ciertamente vulgar, pero bastante representativa de la importancia del pene en la economía del poder masculino:

[...] cuando creyó que ya lo había mirado bastante, levantó hacia mí los ojos y abriendo bruscamente las piernas, pasó su mano sobre la bragueta del pantalón en un gesto entre amenazante y prometedor, mientras sonreía con sus dientes blancos y perfectos, de una manera desvergonzada. (Arredondo, 2002c, p.146)

El poder masculino simbolizado únicamente por el sexo no está por ello reducido. Por el contrario, se amplía, aunque sea solo a través de la vulgaridad y de la violencia. En efecto, se ve como naturalizado: "mi sexo justifica mi poder", parece decirle el falócrata a su víctima estupefacta. Esta presencia pasa a ser para él una prueba tangible de su masculinidad y, en consecuencia, de su virilidad. Así pues, de manera inconsciente, lo que lo hace aún más pernicioso, el propio esquema del falocentrismo se encuentra invertido: mientras que la importancia concedida al pene se inscribe en una política de dominación, dicho órgano se convierte repentinamente en el fundamento mismo 
de una supuesta superioridad masculina. Hay, en efecto, como afirma Pierre Bourdieu, una tendencia a "naturalizar" lo que en su origen no es más que una norma cultural (2007, p. 36-37).

Como destaca por su parte Samuel Ramos, los menos afortunados, los desposeídos de prestigio y de dinero, hacen entonces del pene un cetro, un objeto fetiche, el signo emblemático de un poder que se justifica a sus ojos por el único hecho de ser "macho":

Aun cuando el "pelado" mexicano sea completamente desgraciado, se consuela con gritar a todo el mundo que tiene "muchos huevos" (así llama a los testículos). Lo importante es advertir que en este órgano no hace residir solamente una especie de potencia, la sexual, sino toda clase de potencia humana. (1934, pp.73-74)

No es esta, sin embargo, la única conclusión a la que llega Samuel Ramos, pues este autor identifica también uno de los arquetipos más vivaces de la iconografía masculina: el "macho". Se trata de un estereotipo de gran importancia y alrededor del cual gira la trama de varias de las obras de Arredondo y, en particular, el cuento titulado 2 de la tarde.

\section{3. "Pelado" y "macho"}

A principios de los años 30, Samuel Ramos, joven filósofo de unos treinta y tantos años, propone revelar a sus contemporáneos "el resorte fundamental del alma mexicana" $(1934$, p.69) gracias a las teorías novísimas, en aquel entonces, de Alfred Adler, antiguo discípulo de Freud. La culminación de sus trabajos, publicada en 1934 con el sobrio título de El perfil del hombre y la cultura en México, en realidad forma parte de una larga tradición de ensayos filosóficos, sociológicos, psicológicos o políticos (no siempre exentos de racismo) que, de Ezequiel Chávez a José Vasconcelos en México, y del barón de Keyserling a Gobineau en Europa, intentaron definir el "alma nacional" (Machillot, 2013). Hoy en día, sin embargo, son bien conocidos el impacto y las consecuencias desastrosas que llegaron a tener algunos de estos escritos en varios países.

Por su parte, la obra de Ramos tuvo un gran alcance. Tanto así, que se volvió indispensable para todos los que, años después, desearan examinar los fundamentos de la identidad mexicana. En 
diferentes momentos, el poeta y ensayista Octavio Paz (1998), el psicoanalista Santiago Ramírez (2004) el intelectual Carlos Monsiváis (2004, 2006) y el antropólogo Roger Bartra (2003) han abordado dicho ensayo -aunque fuera, en algunos casos, solo para criticarlo-, mostrando especial interés en la descripción del "pelado" que desde 1934 esbozara Samuel Ramos.

Es este un calificativo que sirve para designar a un individuo "de baja condición social, sin educación [...] que acostumbra hacer y decir groserías, que es irrespetuoso" (Diccionario del español usual en México, 2002, p. 686). "Pelado" se aplica pues, en la actualidad, a una persona pobre y vulgar. Esta definición relativamente reciente parece corresponderse -a primera vista, y excepto por la precisión geográfica y urbana ofrecida por Ramos- a la explicación que se puede leer en EI perfil del hombre y la cultura en México:

Su nombre lo define con mucha exactitud. Es un individuo que lleva su alma al descubierto, sin que nada esconda sus más íntimos resortes. Ostenta cínicamente ciertos impulsos elementales que otros hombres procuran disimular. El "pelado" pertenece a una fauna social de categoría ínfima y representa el desecho humano de la gran ciudad. (Ramos, 1934, p.71)

No obstante, el filósofo va más allá en su descripción, representándonos al "pelado" como un ser acomplejado que compensa su sentimiento de inferioridad a través de la violencia ${ }^{7}$, y su ausencia de cualidades reales por la virilidad y el poder que proyecta sobre ésta:

Es como un náufrago que se agita en la nada y descubre de improvisto una tabla de salvación: la virilidad. La terminología del "pelado" abunda en alusiones sexuales que revelan una obsesión fálica, nacida de considerar el órgano sexual como símbolo de la fuerza masculina [...]. El falo sugiere al "pelado" la idea del poder. De aquí ha derivado un concepto muy empobrecido del hombre. Como él es, en efecto, un ser sin contenido

\footnotetext{
7 "Es un ser de naturaleza explosiva cuyo trato es peligroso, porque estalla al roce más leve. Sus explosiones son verbales, y tienen como tema la afirmación de sí mismo en un lenguaje grosero y agresivo [...] El 'pelado' busca la riña como un excitante para elevar el tono de su 'yo' deprimido." (1934, pp.71-72).
} 
substancial, trata de llenar su vacío con el único valor que está a su alcance: el del macho. (Ramos, 1934, pp.72-74)

"Macho": palabra que se utiliza y que, a través del tiempo, se irá imponiendo poco a poco sobre el término del "pelado", descrito por Ramos. Sin embargo, será este último el término empleado por Inés Arredondo en el cuento 2 de la tarde: "hay muchas a las que les da vergüenza gritar ipelado! porque todo el camión se da cuenta y nomás se ponen coloradas y se encogen" (Arredondo, 2002c, p.114).

$\mathrm{Y}$ es, precisamente, este comentario del héroe del relato el que define su condición. En efecto, gracias a la indeterminación que autoriza el empleo del estilo indirecto libre, se pasa del punto de vista del narrador al soliloquio del protagonista masculino. Monólogo interior que, por otra parte, no hace más que retomar de un modo personal las características atribuidas a los "pelados". Es por esa razón que este "héroe", que acosaba cínicamente, sin mostrar el menor pudor ni la menor vergüenza, a una joven en una parada de autobús: "La muchacha había quedado muy cerca de él; se arrimó a ella con disimulo y le pasó la mano a lo largo del muslo" (Arredondo, 2002c, p.113), comienza a perder un tanto de su orgullo cuando la chica lo mira ostensiblemente de arriba a abajo:

Entonces se dio cuenta de que ella lo observaba y mentalmente fue repasando su aspecto: traje azul marino, la camisa blanca un poco sucia, la corbata de flores, los zapatos negros con tacones gastados, y los calcetines a rayas rojas, azules, verdes, amarillas. Sintió vergüenza como si estuviera desnudo. Se había visto con aquellos ojos ajenos, serenos, diferentes. Enrojeció y se volvió de espaldas a ella. (Arredondo, 2002c, p.113)

Al descubrir su pobreza en el espejo de la mirada del otro, se aferra pues a su virilidad como a un "salvavidas", hundiéndose en la homofobia con el único fin de darse valor a sus propios ojos: "era un hombre pobre, seguramente no le habría parecido bien por eso, pero era mucho mejor que los señoritingos que iban al Departamento a sacar la licencia de manejar, tan alicusados, tan cucos, 
maricas todos" (Arredondo, 2002c, p.113). Tras el discurso homofóbico, pasa bruscamente a la misoginia, a la acumulación de clichés contra las mujeres, compensando con la agresividad su propio sentimiento de inferioridad:

No debía de ser rica, pero todas las muchachas que no parecen gatas, y las que lo parecen también, quieren pescar un millonario, ir al Departamento a sacar una licencia que no sabe uno cómo se las dan, pues no se ha visto nunca ni una sola que sepa estacionarse, y luego andan muy orondas atropellando cristianos. (Arredondo, 2002c, p.113)

Gracias a los insultos, recupera un poco de su confianza en sí mismo e imagina que es jefe; un poder económico y una posición social prestigiosa que tendrían el único propósito de concretar sus fantasías falocráticas:

Si él llegaba a ser jefe del Departamento, aunque no fuera militar [...] prohibiría de plano que manejaran las mujeres iCómo se iban a poner!, irían a chillar como ratas frente a la puerta de su despacho, y él nada más voltearía y las miraría un momento por encima del hombro [...] pero a ésta cuando llegara le daría muy amable una oportunidad única, y personalmente la sometería a la prueba: reversa, fíjese en esa señal, estaciónese, ¿cómo?, cinco metros son más que suficientes [...]. Se pondría humildita, bajaría los ojos... (Arredondo, 2002c, p.113-114)

Según Ramos, en 1934 el "pelado" ya era un estereotipo: "no hablaremos de su aspecto pintoresco, que se ha reproducido hasta el cansancio en el teatro popular, en la novela y en la pintura" (1934, pp.71). En 1979, Inés Arredondo lleva aún más lejos la caracterización: el "pelado" se vuelve a la vez grotesco y patético. Ahora bien, su crítica no va dirigida exclusivamente a los más pobres; también ridiculiza al hombre rico, al "macho" arrogante. Y es que el falócrata trasciende las clases, es el fruto de una norma, el producto de una sociedad más que de un estatus social.

\section{El hombre proveedor}


La cuestión de la igualdad entre hombres y mujeres en el trabajo y la división de tareas ha formado una parte fundamental de las luchas feministas. Este problema, todavía actual, se refleja en la obra de Arredondo.

Mientras que la mujer se circunscribe al espacio familiar, a los quehaceres domésticos y a la educación de los niños, o peor aún, se le confina al papel de amante y mantenida, el hombre, cuando no es estudiante, ocupa en general una posición social y económica privilegiada. Así lo demuestran algunos de los personajes de Arredondo, como el padre ingeniero de Minou en La Extranjera, o el profesor Wassermann de Canción de cuna.

Cuando no se indica esta situación por un título o una función, se le sugiere por signos externos de riqueza, como en los casos de Leonardo en Estar vivo, de Fernández en Flamingos, de Benjamín en El amigo, del novio anónimo de Para siempre, de Roberto Uribe en La casa de los espejos, del tío de La sunamita, etc. La lista sería interminable, pero hay que reconocer que la mayoría de estos personajes evolucionan en un medio urbano, en el seno de una clase privilegiada o incluso dominante. En las escenas rurales, se encuentra la misma propensión a describir a grandes latifundistas.

Es que la riqueza es también un signo de poder $y$, como se puede adivinar, sexo y dinero forman una pareja singular en el abanico de las representaciones masculinas. El dinero sirve, por ejemplo, para convencer a Luisa, la heroína de La sunamita de que se case con el tío moribundo. Es pues, un símbolo que le permite al sexo masculino reforzar o incluso justificar su dominación.

Así pues, en Flamingos, el dinero es el agente: "después de todo no importaba la frase, lo importante era que se diera cuenta de que estaba dispuesto a pagar su elegancia, sus caprichos, porque, precisamente, él no era un don nadie." (Arredondo, 2002a, p.66). Como puede pagar, Fernández está seguro de poder comprar, dándole a Silvia el estatus de objeto. Con sus largas piernas y su caminar elástico, ella es el flamenco rosado, la presa que él sueña enjaular en su lujosa residencia. De ese modo, a la demostración de virilidad se añade la exhibición de la riqueza. En la mascarada que es la ostentación de lo viril, el dinero es un instrumento de peso que permite 
adornar la máscara y también compensar el sexo y la seducción cuando estos últimos fallan, sobre todo, por cuestiones de edad. El ejemplo de La sunamita es bastante elocuente en ese sentido.

Por último, para parafrasear una de las teorías de Guy Debord, tomada de La Sociedad del espectáculo $(1996)^{8}$, el hombre que se dice hombre renuncia a menudo a ser para tener y sobre todo parecer, como lo hemos podido constatar en sucesivas ocasiones en cuentos como Flamingos o, en menor medida, en 2 de la tarde. Parecer en lugar de ser auténtico es, pues, el leitmotiv de muchos de los personajes masculinos en los relatos de Arredondo.

\section{El hombre que impone su propia visión}

Algunos autores ya han destacado la importancia de la mirada en la obra de Arredondo (Arenas, 2002), en la que los personajes masculinos también parecen aspirar a encontrar aquello que desean proyectar en el reflejo de la mirada de las mujeres. Sin embargo, cuando el género masculino construye un reflejo de sí mismo, lo que busca es una relación egoísta y narcisista. Cada vez que el hombre se mira en los ojos de su pareja lo que quiere ver ahí es su reflejo en un espejo pulido, una imagen sublime y complaciente. No aspira a la autenticidad -valor que Lacan pone en duda-ya que lo que le complace es ver esta versión artificial de sí mismo. Como su ambición es solo el tener y el parecer, el ser le es ajeno en la mayoría de los relatos. Esta imagen, reevaluada con cada nuevo éxito (o "conquista"), crece hasta que sobrepasa un marco que deja entonces de considerar digno, lo que le lleva a buscar otros espejos, otros seres.

"Conquistas"; término éste con un sinnúmero de connotaciones, ya que no se trata solo de verse, sino de "ocupar" la mirada del Otro, imponiendo la figura propia en un espejo hasta cierto punto "violado", y, si es preciso, "destruido", con tal de poderse encontrar en él, pues, ciertamente, incluso en la fragmentación la imagen se multiplica. La mujer, por su parte, se ve tan relegada a esta función psicológica de espejo, que al final se rompe, como relata la heroína y narradora del cuento En la sombra:

\footnotetext{
${ }^{8}$ Citado en francés en el original: La Société du spectacle. N.d.t.
} 
Pasó sobre mí los ojos para que pudiera ver su mirada radiante. Y fue precisamente en esa mirada donde vi que todo aquello era mentira. A él le hubiera gustado que se tratara de una felicidad verdadera y la actuaba con fidelidad; pero seguramente, si no estuviera yo delante siguiendo con aguda atención todos sus gestos, no hubiera sido la mitad de dichoso. Había algo demoniaco en aquella inocencia aparente que fingía ignorar mi existencia y mi dolor. (Arredondo, 2002c, p.143) ${ }^{9}$

Para el falócrata, la mujer no es más que un fuego fatuo, un espejo ardiente en el que sacrificar fugaces y sádicos deseos, por naturaleza insaciables, puesto que se sabe desde Freud que el deseo es indisociable de la falta, y que se manifiesta para luego desaparecer en incontables horizontes imposibles. Así pues, a menudo en los cuentos de Arredondo, mientras que la mujer solo aspira a encontrar en los ojos de su amante un reflejo tierno y sincero de sí misma, la mirada del hombre la juzga, la censura y la remite a otro ícono, también idealizado, de la feminidad, pero tal y como él la concibe y a la cual le gustaría verla ajustarse, como es el caso de Fernández, en Flamingos, o de Ismael, el héroe de Atrapada, quien le dice a su esposa: "Hay veces en que se necesita sacrificar la belleza natural para transformarla en algo nuestro, acorde a nuestro ser" (Arredondo, 2002c, p.170).

Sin embargo, la mujer ideal, nacida de la imaginación y de deseos siempre fluctuantes, sigue siendo un espejismo inaccesible que ningún ser puede encarnar a largo plazo. Así pues, después de que la heroína de El amigo ha hecho toda clase de cosas para satisfacer a su amante, éste, una vez pasada la novedad, la abandona cruelmente. En Atrapada, Paula también intenta ajustarse a los deseos de su esposo:

Nadie me obligó, yo sola empecé a vivir para esperar a Ismael. Sin embargo mis lentas horas de soledad no estaban vacías, mi deseo de ser tal como él quería que fuera las Ilenaba: leía, asistía a clases, a conferencias, escuchaba música, y por encima de todo lo observaba y lo comparaba conmigo, pobre de mí. (Arredondo, 2002c, p.169)

\footnotetext{
${ }^{9}$ Texto destacado en cursiva por el autor del artículo.
} 
Todo en vano, ya que a los ojos de Ismael todas las otras mujeres eran más atractivas que la que se entregaba completamente a él:

Su voz era incisiva y vi brillar en sus ojos el pequeño triunfo que siempre se agolpaba en ellos cuando comentaba sobre el atractivo, la guapura o la inteligencia de las otras mujeres, porque él se daba cuenta de que yo no participaba de las ventajas genéricas o particulares de mi sexo. (Arredondo, 2002c, p.182-183)

\section{Conclusión}

Como hemos visto, la ley paterna es, según Lacan, un principio organizador de la cultura, puesto que estructura todos los significados del lenguaje. En ese sentido, nos dice, el orden simbólico es esencialmente androcéntrico: es la ley paterna la que prohíbe el incesto entre la madre y su hijo, y es precisamente esta prohibición, la que condiciona las bases de la construcción del individuo.

Por su parte, Judith Butler (2005), sostiene que este orden simbólico es claramente falocéntrico y está basado en un conjunto de leyes que regulan el parentesco y el significado, así como las diferencias sexuales.

Al respecto, como lo pudimos constatar en el presente trabajo, estas prohibiciones y estas leyes no se ejercen sin violencia: se vuelven despóticas en relatos como La casa de los espejos o Canción de cuna; aparecen simbolizadas en su totalidad por el pene, como en Olga; son vulgares y agresivas como en 2 de la tarde; se personifican en el hombre proveedor, amo del destino de las mujeres, como en La sunamita; o en el hombre que aparenta para imponerse física y visualmente, como en En la sombra (Arredondo, 2002c).

La única manera de escapar de la violencia masculina, no parece ser otra que el amor que, aunque es escaso, es aun así capaz de romper la soledad siempre que es recíproco. A pesar de esto, por lo general, el destino de las mujeres enamoradas en la obra de Arredondo es el abandono, el sufrimiento, la locura o incluso el mal, ya que, mientras que el hombre tiene el poder de imponer "su visión de sí mismo" para convertirse, como destaca Bourdieu en un "sujeto absoluto" (Bourdieu, 
2007, p.89), la mujer termina siempre perjudicada. Al final, no se reconoce a sí misma en la mirada del hombre, la realidad en la que vive es, para citar a Arredondo, amorfa ${ }^{10}$ y se siente "rota".

\section{Referencias:}

Albarrán, C. (2000). Luna menguante: vida y obra de Inés Arredondo. México: Ediciones Casa Juan Pablos.

Arenas, R. (2002). La pareja y la mirada transgredida en 'Mariana' de Inés Arredondo. En Labastida, J. (Ed.), Inés Arredondo. México: Siglo veintiuno editores.

Arredondo, I. (2002a). La señal. En Labastida, J. (Ed.), Inés Arredondo. México: Siglo veintiuno editores.

Arredondo, I. (2002b). Los espejos. En Labastida, J. (Ed.)., Inés Arredondo. México: Siglo veintiuno editores.

Arredondo, I., Río subterráneo. En Labastida, J. (Ed.). (2002c), Inés Arredondo. México: Siglo veintiuno editores.

Bartra, R. (2003). La jaula de la melancolía. Identidad y metamorfosis del mexicano. Mexico: Grijalbo.

Bourdieu, P. (2007), La dominación masculina. Barcelona: Editorial Anagrama.

Bradu, F. (1987). La escritura subterránea de Inés Arredondo. En Señas particulares: escritora. México: Fondo de Cultura Económica.

Butler, J. (2005). Trouble dans le genre. Paris: Éditions La Découverte.

Corral, R. (2002). Inés Arredondo: la dialéctica de lo sagrado. En Labastida, J. (Ed.). (2002), Inés Arredondo. México: Siglo veintiuno editores.

Debord, G. (1996). La Société du spectacle. Paris: Editions Gallimard.

Diccionario del español usual en México (2002). México: El Colegio de México.

\footnotetext{
10 "Creo que si uno no es mirado, es decir reconocido, no puede tener más que una realidad amorfa." Inés Arredondo en entrevista con Fabienne Bradu (1987, p.30).
} 
Domínguez, C. (1996). Antología de la narrativa mexicana del siglo XX, t. 2. México: Fondo de Cultura Económica.

Garza, A. (2001). La(s) representación(es) de la subjetividad femenina a través del palimpsesto en 'La sunamita' y 'Estío' de Inés Arredondo. The Rocky Mountain E-Review of Languages and Literature. 55.1. Obtenido el 12 de diciembre de 2012 de http://www.rmmla.org/assets/docs/Journal-Archives/2000-2009/55-1-2001agarzaa.pdf

Labastida, J. (Ed.). (2002), Inés Arredondo (4ta edición). México: Siglo veintiuno editores.

Lacan, J. (1978), Le moi dans la théorie de Freud et dans la technique de la psychanalyse, Paris: Éditions du Seuil.

Machillot, D. (2013). Machos y machistas: historia de los estereotipos mexicanos. México: Planeta.

Machillot, D. (2006). Visions féminines de la domination masculine ? Genre et écriture dans l'œuvre d’Inés Arredondo. (Tesis de maestría inédita, Université de Poitiers).

Martínez, M. (2004). La aventura trágica en Inés Arredondo. Revista Casa del Tiempo mayo 2004. Obtenido el 15 de enero de 2011 de http://www.difusioncultural.uam.mx/revista/mayo2004/mabelmartinez.html

Monsiváis, C. (2006). Imágenes de la tradición viva. México: UNAM/Fondo de Cultura Económica.

Monsiváis, C. (2004). Escenas de pudor y liviandad. México: Debolsillo.

Paredes, A. (1990), Figuras de la letra. México: UNAM.

Paz, O. (1998). El laberinto de la soledad (5ta ed.). México: Fondo de Cultura Económica, 1998.

Pérez, A. (1988). La anulación del yo en "La Sunamita”. Semiosis, no. 20, 1988

Ramírez, S. (2004). El mexicano, psicología de sus motivaciones. México: Ediciones Debolsillo.

Ramos, S. (1934). El perfil del hombre y la cultura en México. México: Imprenta Mundial. 